\title{
Criatividade com avatares na Prática Educativa Supervisionada
}

\section{Creatividad con avatares en la práctica educativa supervisada}

Paula Alves de Quadros-Flores Escola Superior de Educação do Politécnico do Porto paulaqflores@ese.ipp.pt

Margarida Campos Marta Escola Superior de Educação do Politécnico do Porto margaridamarta@ese.ipp.pt

Susana Marques de Sá Escola Superior de Educação do Politécnico do Porto susanasa@ese.ipp.pt

Fecha de recepción 2018-12-16

Fecha de aceptación 2018-12-27

Quadros-Flores, P.; Campos Marta, M. \& Marques de Sá, S. (2018). Criatividade com avatares na Prática Educativa Supervisionada. Revista Practicum, V3(2), 60-76 


\section{Resumo}

Inovar exige mudanças nos modos de ensinar a aprender a aprender por forma a desenvolver competências imprescindíveis no século XXI. A criatividade é uma dessas competências necessárias para encontrar novas soluções para velhos problemas. No âmbito da formação inicial docente, estudantes em situação de estágio, no mestrado em Educação Pré-Escolar e Ensino do 1.0 Ciclo do Ensino Básico, tiveram conhecimento de uma aplicação digital que permite criar avatares. Este estudo pretende compreender a criatividade dos estudantes estagiários do segundo ano de Mestrado em Educação Pré-Escolar e Ensino do 1.0 Ciclo do Ensino Básico pelo modo como esta ferramenta foi utilizada nos dois níveis educativos e o impacto no processo de ensino e aprendizagem. Recorreu-se a uma abordagem de natureza qualitativa e usou-se a análise de conteúdo como instrumento de recolha de dados de relatórios de estágio de 22 estudantes, correspondendo a 38 práticas relativas ao 10 Ciclo do Ensino Básico (10 CEB) e cinco à Educação Pré-escolar (EPE), relativos ao ano de 2016/2017. Os resultados mostram a relevância do recurso tecnológico nas práticas educativas ao nível da motivação, da atenção, da concentração e desempenho das crianças e ao nível da reinvenção das práticas dos docentes. Contudo, verificou-se que o enfoque ainda está centrado na utilização da ferramenta tecnológica pelo docente e com menor impacto na alteração do papel da criança enquanto criadora de recursos digitais.

\section{Resumen}

Innovar exige cambios en los modos de enseñar cómo aprender a aprender para desarrollar competencias imprescindibles en el siglo XXI. La creatividad es una de esas competencias necesarias para encontrar nuevas soluciones a viejos problemas. En el ámbito de la formación inicial docente, estudiantes de Prácticum en el master en Educación Infantil y Primer Ciclo de Enseñanza Básica, conocieron una aplicación digital que permite crear avatares. Este estudio pretende comprender la creatividad de los estudantes en prácticas según el modo en que esta herramienta se utilizó en los dos niveles educativos y el impacto en el proceso de enseñanza y aprendizaje. Se recurrió a un enfoque de naturaleza cualitativa y se utilizó el análisis de contenido como instrumento de recogida de datos de informes de prácticas de 22 estudiantes, correspondiendo a 38 prácticas relativas al 10 Ciclo de la Enseñanza Básica (10 CEB) y cinco a Educación Infantil (EPE), relativos al curso académico 2016/2017. Los resultados muestran la relevancia del recurso tecnológico en las prácticas educativas tanto sobre la motivación, la atención, la concentración y el desempeño de los niños/as, como sobre la reinvención de las prácticas de los docentes. Sin embargo, se verificó que el enfoque aún está centrado en la utilización de la herramienta tecnológica por parte del docente y con un menor impacto en la modificación del papel del niño/a como creador de recursos digitales. 


\section{Palavras-chave}

Formação inicial docente, tecnologias digitais, criatividade, renovação metodológica, estágio.

\section{Palabras claves}

Dormación inicial docente, tecnologías digitales, creatividad, renovación metodológica, practicum.

\section{Introdução}

Mais de trinta anos após as primeiras iniciativas sobre a inclusão das Tecnologias de Informação e Comunicação (TIC) na educação, como ocorreu com o projeto Minerva (Ponte, 1994), questionamo-nos se houve alterações nos modos de ensinar e de aprender na atualidade, sobre os modos de formar o educador/professor e o cidadão do século XXI. O Despacho n. ${ }^{\circ}$ 5908/2017, 5 de julho revela uma mudança significativa nos modos de pensar político, embora o seu objetivo fosse apenas a valorização dos seus agentes, na medida em que reconhece que o "cidadão de sucesso é conhecedor, mas é também capaz de integrar conhecimento, resolver problemas, dominar diferentes linguagens científicas e técnicas, coopera, é autónomo, tem sensibilidade estética e artística e cuida do seu bem-estar". Ao centralizar a escola e seus atores na gestão flexível e contextualizada do currículo (Despacho n.o 6478/2017, 26 de julho) e ao introduzir o perfil dos alunos (OliveiraMartins, 2017) estimulou a metodologia de projeto e, por sua vez, a abertura da escola ao mundo.

Este contexto potencia a queda de metodologias tradicionais e um novo pensar metodológico que dá oportunidade à transversalidade curricular e a um pensar a ação educativa de modo global, promotora de desenvolvimento de competências de nível mais elevado, como é objetivo do Ministério da Educação. Contudo, a mudança é um processo complexo que impõe tempo de aquisição, de preparação e de criação. Segundo Quadros-Flores e Raposo-Rivas (2017), face a ambientes tecnológicos o crescimento profissional dos docentes realiza-se por etapas flexíveis: etapa da descoberta, etapa da experimentação, etapa da mudança e etapa seletiva. Nas duas primeiras etapas os docentes adotam uma metodologia tradicional adaptada, havendo uns educadores/professores que usam a tecnologia como mais um recurso, mas sem alteração do modelo metodológico, e outros que adaptam a metodologia ao recurso sem implicação de mudança de perfil de professor e de aluno. Na etapa de mudança os educadores/professores experimentam novos modos de ensinar a aprender alterando o paradigma tradicional. A maturidade metodológica ocorre na fase da seleção cujas práticas revelam ser inovadoras, inclusivas, democráticas, transferíveis, e impulsionadoras do 
desenvolvimento de competências que respondem às exigências do século XXI, práticas que (re)desenham um novo perfil do docente e das crianças.

As tecnologias da informação e da comunicação são potenciadoras dessa mudança, não só porque respondem aos interesses desta nova geração, mas também porque as suas caraterísticas potenciam a transversalidade dos saberes e do desenvolvimento de competências. Existem milhares de artigos pelo mundo que revelam mudanças nos modos de ensinar e de recursos utilizados, embora uns ainda espelhem o paradigma tradicional, apesar de usarem novos recursos, incluindo digitais, outros já são mais ambiciosos e reveladores de mudanças nos objetivos e processos. Esta mudança é visível nos eixos temáticos das conferências e congressos que solicitam práticas inovadoras com TIC, em ambientes virtuais e integradores, articulando o desenvolvimento das dimensões formal, não formal, informal do ensino, da formação e da aprendizagem, com abordagens que tocam a Inteligência artificial, a programação e robótica, eLerarning, Learning Analytics e Big Data, Flipped Classrom, redes socias, avaliação de competências com tecnologia emergente, etc. Mas também práticas que valorizem a preparação dos cidadãos para um mundo global, incerto, em rápida mudança. Note-se que, embora se valorize a utilização de recursos TIC, há uma valorização maior da educação e dos modos de aprender, há uma visão sociocultural mais sustentável, já que o sucesso do cidadão depende fortemente da sua capacidade de inovar, de criar valor ao seu redor, pelo que desenvolver competências como o pensamento crítico, criativo, decisivo e empreendedor é importante.

No âmbito da educação, a implementação do processo de Bolonha provocou, ao nível global, mudanças na formação inicial com o objetivo de construir um espaço europeu de ensino superior, exigindo uma reestruturação, centrada na aprendizagem do estudante, "(...) um novo modo de ensinar e um novo modo de aprender consigo, com os outros e com o meio envolvente" (Dotta et al, 2013, p. 153). Neste sentido, estamos perante uma nova qualificação profissional exercida na perspetiva de uma ação docente empreendedora e incitadora de práticas inovadoras (Flores, Escola, \& Peres, 2012; Flores, Escola, \& Peres, 2013).

Se a autonomia dos estudantes trouxe olhares mais interpretativos, provocou, também, alterações significativas na sua aprendizagem. Contudo, estudos realizados no âmbito da formação inicial docente evidenciam que os futuros docentes se sentem pouco preparados para enfrentar as realidades dos contextos educativos evocando mais a sua experiência pessoal enquanto crianças do que a relação teoria-prática ao longo da formação inicial (Flores, 2010; Korthagen, Loughran \& Russel, 2013). Para se diminuir este impacto a investigação deve ganhar um lugar de destaque na prática supervisionada educativa onde os estudantes problematizem "(...) o processo de tornar-se professor no sentido de uma (re)construção pessoal do conhecimento sobre o ensino (que contrarie a lógica prescritiva e procedimental ainda prevalecente nalgumas conceções de crianças -futuros professores) com implicações para a (trans)formação da identidade profissional" (Flores, 2010, p. 186). Importa que os futuros 
docentes se assumam como investigadores das suas próprias práticas educativas sendo capazes de refletir sobre elas e reinventar-se a si e aos contextos, num ciclo espiral e dinâmico de observação, planificação, ação, reflexão e avaliação (Latorre, 2003), promotor do desenvolvimento profissional do educador e do professor, "colocando-se ao serviço de uma educação transformadora" (Vieira \& Moreira, 2011, p. 59).

A perspetiva do futuro docente enquanto investigador abre portas para a transformação (Shulman, 2014) do conhecimento, das pedagogias e dos modos de agir (Nóvoa, 1991, 2002). Porém, como referem Flores e Ramos (2016, p. 196) transformar requer "inovar, recriar e redesenhar" que são atos que "favorecem um contexto de mudança, atitudes que exigem capacidade de fazer diferente e que geram novas ideias e novas maneiras de viver a educação e que têm o seu elenco na prática educativa supervisionada e no relatório de estágio". Ou seja, o paradigma tradicional já não responde aos novos desafios da sociedade atual que impõe informação e conhecimento, além de outras competências definidas no perfil dos alunos (Oliveira-Martins, 2017), para responder à complexidade, diversidade e incertezas do futuro.

A mudança de paradigma requer, para além do conhecimento, a criatividade como uma competência que exige a mobilização de saberes e capacidade para a disrupção. Para Ribeiro (2018) "a criatividade não é algo de geneticamente pré-determinado", pelo que o autor realça que "(...) se as instâncias educativas cuidassem do desenvolvimento da criatividade e do gosto de criar como cuidam da aquisição de conhecimentos e dos modos de ensinar e aprender" (p. 256), então as novas gerações teriam mais iniciativa, mais responsabilidade no "novo imperativo categórico do desenvolvimento" (Lipovetsky, citado por Ribeiro, 2018, p.255). Assim, a formação inicial docente deverá investir de forma mais explícita no desenvolvimento da criatividade nos futuros docentes, uma vez que "para favorecer o desenvolvimento da criatividade das crianças é importante contar com professores motivados a utilizar práticas pedagógicas criativas; educadores assim motivados servirão de modelo e estímulo ao desenvolvimento do potencial criador dos seus alunos" (Oliveira \& Alencar, 2012, p. 543).

Para estes autores várias são as barreiras para o desenvolvimento da criatividade em contexto escolar tais como: ausência desta vertente na formação inicial, o medo de errar e fracassar, a falta de tempo para preparar as atividades e recursos, falta de apoio da hierarquia institucional e ausência de atualização na formação contínua.

Em Portugal, vive-se um momento complexo em que "a conjuntura política, económica, social e até cultural não motiva a escolha da profissão docente" (Ruivo, 2015, p. 172), sendo a desmotivação e o envelhecimento do corpo docente entraves à mudança de paradigma e inovação das práticas educativas. O impacto que a qualidade das práticas educativas tem na aprendizagem, motivação e resultados dos crianças é inegável e, por isso, as instituições de Ensino Superior na área da formação de professores têm um desafio acrescido na preparação dos docentes do e 
para o futuro, sendo necessário, investir numa "cultura de investigação, com vista ao desenvolvimento de atitudes e competências problematizadoras das práticas educativas" (Martins, 2015, p. 181) e criar percursos de formação que "incentivem o gosto pelas aprendizagens, que alimentem a curiosidade e a motivação dos professores" (idem, p. 187) ". É, neste sentido, que os espaços de estágio têm um papel preponderante na dimensão da criatividade, provocando transformação dos contextos educativos.

\section{Objeto, universo do estudo e desenho metodológico}

O estudo tem como objetivo compreender o modo como uma aplicação digital, Voki (ferramenta digital que permite criar um avatar), foi utilizada na atividade da Educação Pré-Escolar e em sala de aula no $1^{\circ}$ CEB para avaliar a criatividade dos estudantes tendo como categorias o tipo de estratégias utilizadas e seus efeitos nas crianças. Neste contexto, procedeu-se a uma abordagem metodológica de natureza qualitativa que permite compreender os significados dos estudantes, pois os dados são ricos em pormenores descritivos (Bogdan \& Biklen, 1994) e reflexivos relativamente às práticas selecionadas. Para a recolha de informação recorreu-se a 22 relatórios de estágios de estudantes a frequentarem 0 mestrado em Educação Pré-Escolar e Ensino do 1.0 Ciclo do Ensino Básico e utilizou-se a análise de conteúdo como técnica de análise de dados. A opção por esta metodologia deve-se ao facto de a sua função heurística enriquecer a tentativa exploratória, ou seja, aumenta a propensão à descoberta, e a sua função de "administração da prova" servirem de diretrizes para uma confirmação, como refere Bardin (1977, p. 30). As unidades de análise incluirão palavras e frases que definem as estratégias utilizadas e seus efeitos, de acordo com os objetivos do estudo. A informação recolhida nos relatórios de estágio foi analisada e refletida a partir de quatro dimensões que emergiram a posteriori da análise de conteúdo: utilização do avatar no processo de ensino e aprendizagem: como, quando, onde; o papel do avatar na prática educativa; o papel da criança e do docente na prática educativa; impacto do avatar.

\section{Apresentação e discussão de resultados}

A interpretação de cada uma das dimensões permitiu-nos obter impressões sobre o seu conteúdo e significado, ao mesmo tempo, que tomamos consciência da sua amplitude e da sua fragilidade pluridimensional. Apresentamos as dimensões, em subpontos, de forma a evidenciar as potencialidades da criatividade no percurso formativo dos estuantes e no processo ensino aprendizagem das crianças e/ou algum constrangimento do recurso digital - o Voki. 


\subsection{Aplicação do Voki no processo de ensino e aprendizagem: como, quando, onde}

No que diz respeito à sua aplicação em sala de atividade/aula, quisemos compreender as estratégias de utilização pelos estudantes estagiários em diferentes momentos da atividade/aula: início, durante e no final da atividade/aula.

No início da atividade/aula (Figura 1) verificou-se que esta aplicação, independentemente do nível educativo, é mais utilizada para lançar desafios às crianças abrangendo momentos de interação avatar/crianças, numa simulação de diálogo numa única direção, ou seja, - avatar dirige-se à criança de forma natural, mas não consegue responder à mesma se esta o questionar, aqui impõe a intervenção do educador/professor. Também a situação particular de convite para a aventura, como acontece na Educação Pré-Escolar, estimula para a participação e a envolvência das crianças, para um ambiente lúdico que permita "(...) oportunidades de experimentar novas sensações, criar laços sociais, aceder ao conhecimento, aprender a aprender e a ultrapassar obstáculos" (Silva \& Sarmento, 2017, p. 42).

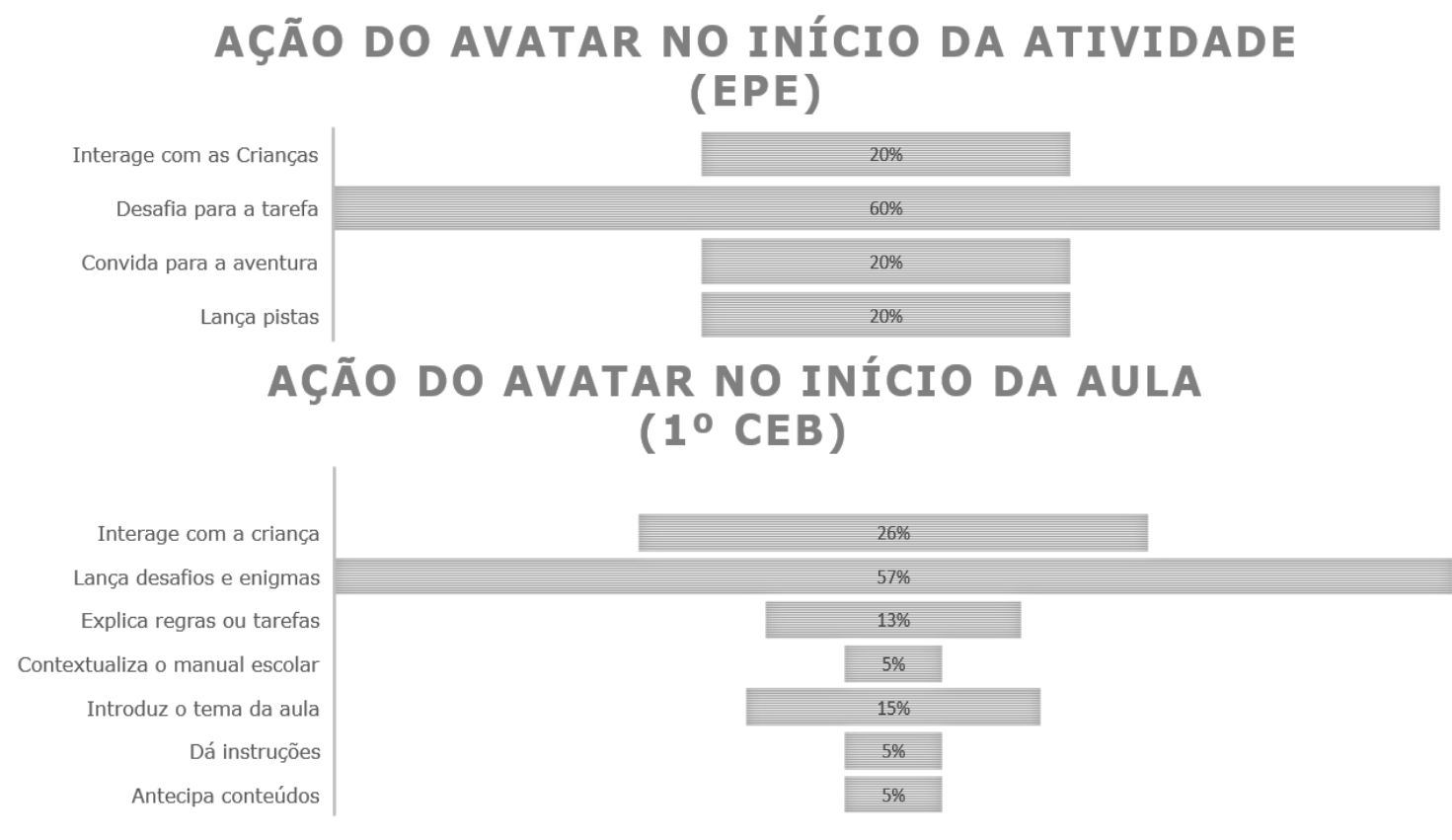

Figura 1. Estratégias de utilização do avatar no início da atividade na EPE e da aula no $1 .{ }^{\circ} \mathrm{CEB}$

Se por um lado, este cenário de desafios e convites lançados às crianças para a resolução de problemas potencia oportunidades de raciocínio e o desenvolvimento de competências (Marta, 2017). Por outro lado, embora menos frequente, revela a encarnação do personagem do 
papel do docente num ambiente mais tradicional: introduz o tema, explica as regras ou tarefas a realizar, dá instruções, antecipa conteúdos e contextualiza o manual escolar.

Este cenário, embora promotor de um ambiente positivo na educação e de entusiasmo da criança, já que é uma figura digital que se dirige à criança assumindo o papel de docente, não deixa de espelhar a fragilidade de uma metodologia centrada no educador/professor. O uso desta ferramenta centra-se, maioritariamente, num nível de motivação extrínseca à criança (criado e apresentado pelo docente), sendo desejável que servisse a motivação intrínseca (criado e apresentado pela criança), sendo esta necessária para o desenvolvimento da criatividade, segundo o modelo proposto por Amabile (in Alencar \& Fleith, 2003).

No que concerne à utilização na Educação Pré-Escolar, durante a atividade educativa, (Figura 2) o avatar continua a desafiar muito expressivamente para a interação e resolução de problemas. Já no 1.0 CEB, verifica-se que é mais utilizado para orientar a compreensão do conteúdo curricular e organização das equipas. Contudo, não deixa de assumir a mesma função de início da aula, embora menos significativamente: desafia, explica, interage, sendo que neste ambiente as crianças delatam os seus conhecimentos prévios relativos aos conteúdos a adquirir.

\section{AÇÃO DO AVATAR DURANTE A ATIVIDADE (EPE)}

\section{AÇÃO dO AVATAR DURANTE A AULA (10 CEB)}

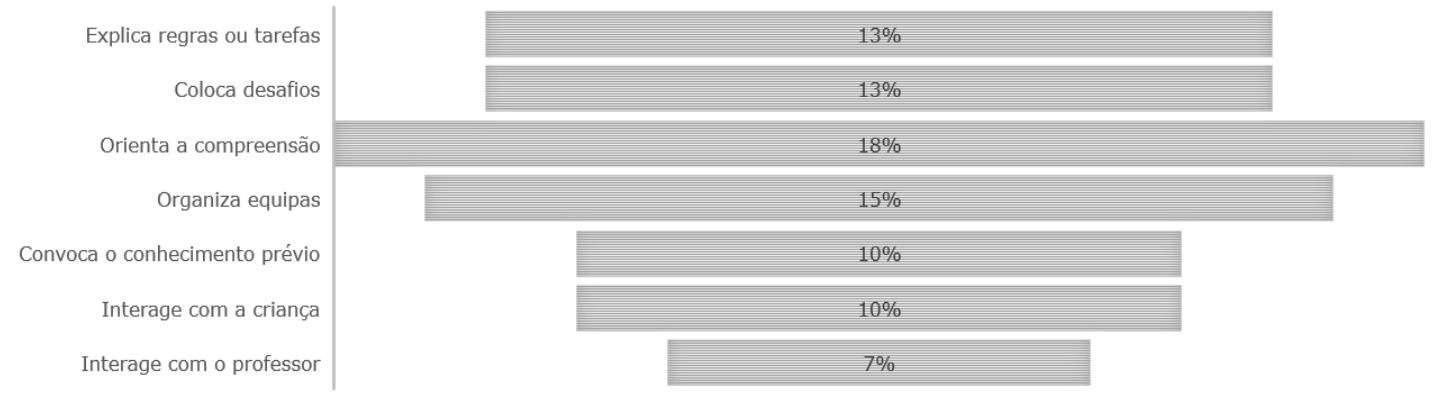

Figura 2. Estratégias de utilização do avatar durante a atividade na EPE e da aula no $1^{\circ} \mathrm{CEB}$

Num terceiro momento (Figura 3), no final da atividade na Educação Pré-Escolar, o avatar confirma se o problema que lançou às crianças foi resolvido e reforça a informação relativa aos conteúdos, permitindo uma articulação de "saberes das várias linguagens" (Marta, 2017, p. 43). 


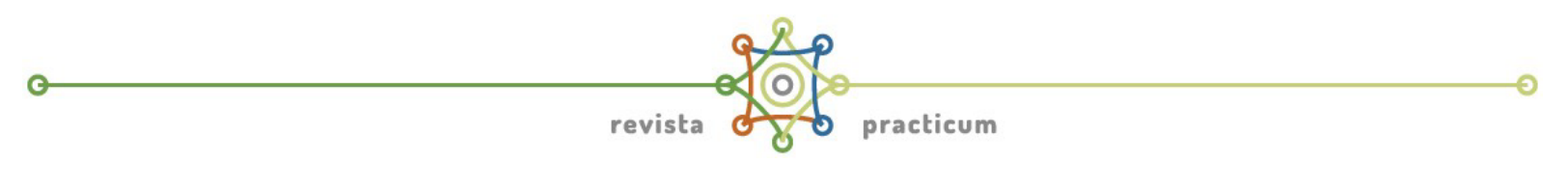

\section{AÇÃO DO AVATAR NO FINAL DA ATIVIDADE (EPE)}

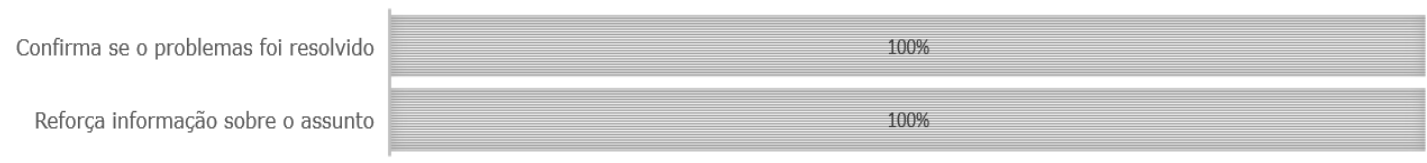

\section{AÇÃO DO AVATAR NO FINAL DA AULA ( $1^{\circ}$ CEB)}

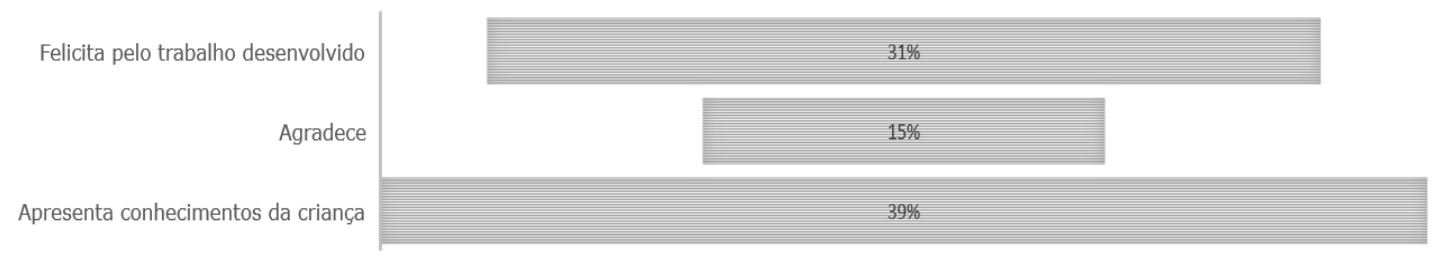

Figura 3. Estratégias de utilização do avatar no final da atividade na EPE e da aula no $1^{\circ} \mathrm{CEB}$

Já no 1.0 CEB serve de recurso para apresentação dos conhecimentos construídos pelas crianças, mas também assume uma atitude de respeito pelo outro, fazendo reforço positivo junto das crianças: felicita e agradece. Verificou-se, ainda, que os estudantes que estavam a estagiar na Educação Pré-Escolar utilizaram o avatar apenas em contexto de sala de atividade, mas no $1 .{ }^{\circ}$ CEB $86 \%$ da sua utilização foi realizada em sala de aula e $14 \%$ foi utilizado fora dela, isto é, na biblioteca, durante o apoio ao estudo e em casa.

\subsection{O papel do avatar na prática educativa}

A análise das reflexões dos estudantes mostra que estes selecionam os avatares de acordo com os objetivos da atividade/aula. Assim, encontramos personagens de obras literárias, personagens de textos do manual escolar, personagens autor de obras e muitas outras personagens relativas sobretudo a temas estudados na área das ciências naturais e sociais, como os animais, as profissões, a natureza, mas também assumindo nomes de crianças, como o António, a Susana, a Joana, etc.

Personagens com as quais as crianças se identificam e permitem uma proximidade entre os atores e autores do processo educativo e, também, entre os diversos recursos, possibilitando desenvolver um "olhar interpretativo, reflexivo e crítico da realidade e uma melhor compreensão pedagógica da integração de tecnologias" no contexto (Marta, 2017, p. 45). Neste sentido, acredita-se que as tecnologias de informação e comunicação, utilizadas nas atividades/aulas, foram "uma mais-valia para 
o desenvolvimento de competências individuais e sociais" da criança (idem, p. 43).

Além disso, verificou-se que (Figura 4) o avatar na Educação PréEscolar assume o papel, em conjunto, com os educadores/estudantes em dois momentos distintos na atividade educativa: desafia no início e durante a atividade, mas confirma no final da atividade se as aprendizagens foram significantes para a criança e, ao mesmo tempo, se provocaram uma reinvenção pedagógica.

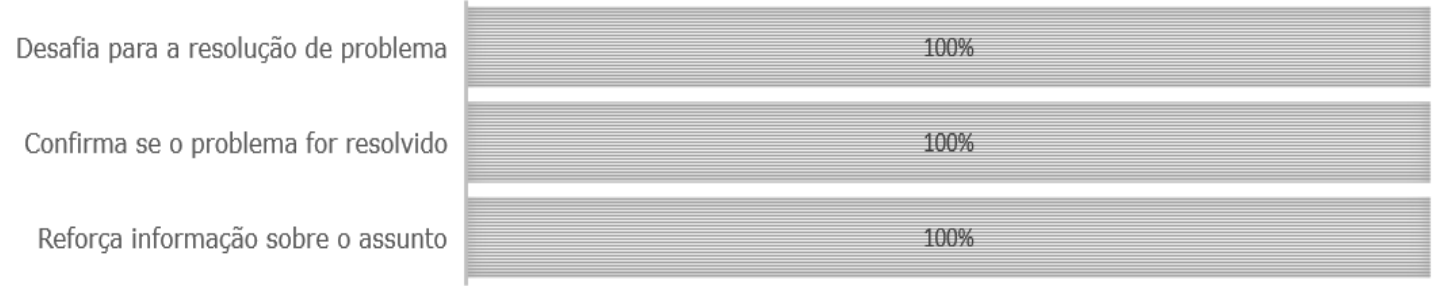

Figura 4. O papel do avatar na EPE

No 1. CBE (Figura 5) o avatar assume diferentes papéis:

- Mais significativamente o de professor na sala de aula lança desafios para desenvolver competências de reflexão e resolução de problemas e de atitudes de escuta e de participação; explica as regras ou tarefas; introduz o tema da aula; orienta a compreensão; estimula a mobilização de conhecimentos; reconhece o trabalho realizado pelas crianças.

- de recurso didático - facilitador da articulação curricular; replica a voz da criança (leitura) lê o texto escrito; fomentador da motivação das crianças.

- $\quad$ de apoio ao professor -apoia na organização dos grupos 

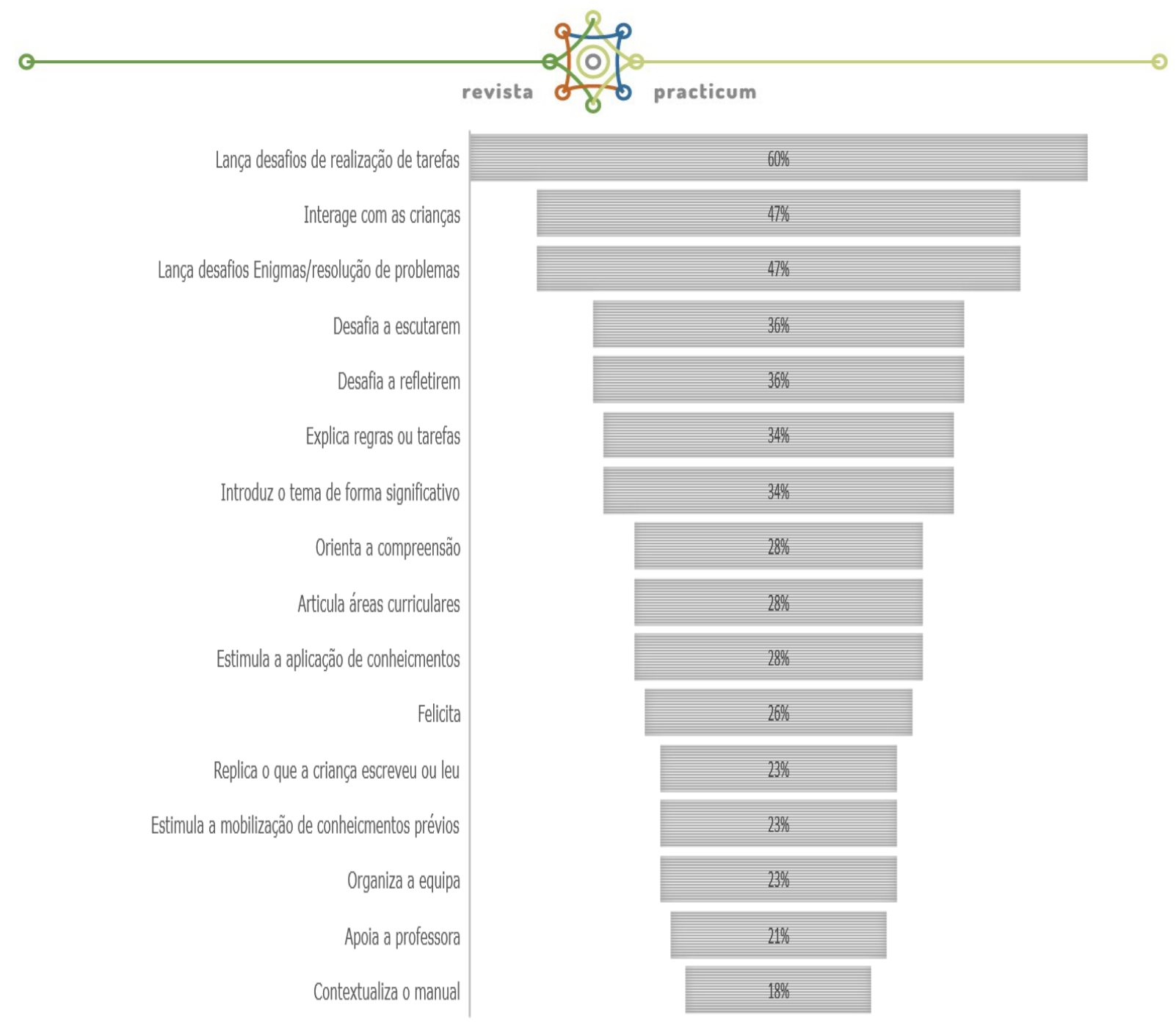

Figura 5. O papel do avatar no $1{ }^{\circ} \mathrm{CEB}$

\subsection{O papel da criança e do docente na prática educativa}

Verificou-se que os estudantes estagiários referem, na Educação Pré-Escolar, que a criança "escuta", "interage", "discute" e "executa". No 1.0 CEB (Figura 6) é mais frequente que a criança execute as tarefas referidas pelo avatar, seguido de escutar o avatar, resolver os problemas e construir avatares. A interação com o avatar é relevante, mas menos significativa, compreende-se este resultado se tivermos em atenção que a comunicação é unidirecional, o avatar dirige-se à criança, mas não responde às questões que esta possa levantar.

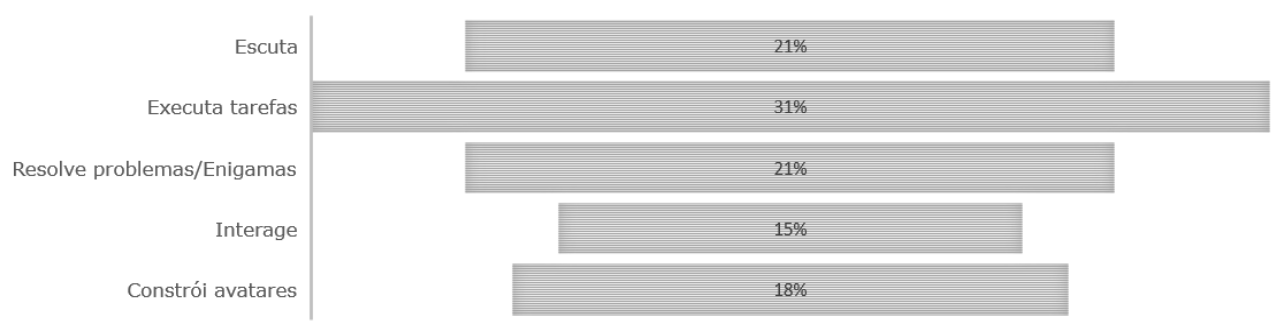

Figura 6. O papel do aluno no $1^{\circ} \mathrm{CEB}$ 
Percebeu-se, na reflexão dos estudantes estagiários, que as crianças constroem avatares dando voz a personagens de textos da área do português, a personagens imaginadas no âmbito do estudo do meio e a personagens criadas que desafiam o raciocínio lógico-matemático. Esta atividade distingue-se das restantes, pois é a criança que constrói, que verifica o resultado e que apresenta aos colegas. Assim, além da atitude de escuta, de participação e interação, de realização de tarefas, esta atividade estimula a criatividade da criança na seleção e construção do avatar, o saber fazer que envolve a leitura e a escrita, facilitando a transversalidade curricular, a literacia digital, e competência de comunicação e interação com o outro.

No que diz respeito ao papel do educador de infância/estudantes, constatou-se que este apresenta o avatar, participa nas atividades por ele orientada e avalia/reflete sobre a atividade educativa. Já no 1.0 CEB (Figura 7), os estudantes estagiários relevam o papel de técnico informático. Compreende-se este resultado já que estes estudantes aprenderam a trabalhar a ferramenta de forma autónoma, resolvendo problemas técnicos nos contextos educativos. Mas também referem que o professor interage com o avatar, apresenta-o, executa tarefas e orienta a aula.

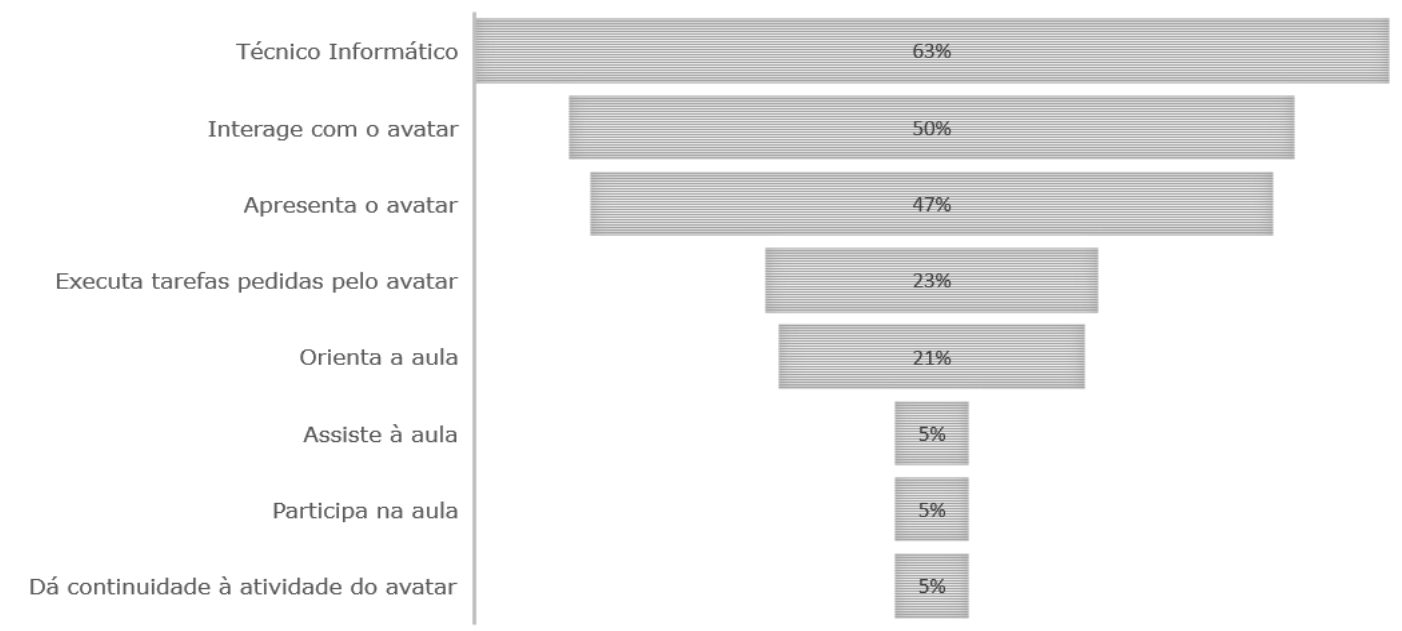

Figura 7. O papel do professor na sala de aula

De facto, como já se referiu, esta aplicação tem um limite de interação, é possível programar a interação com as crianças, mas não reage ao feedback. Exige, assim, algumas técnicas de utilização, pelo que com frequência o professor deve intervir no diálogo assumindo o comando da aula e executando tarefas que o avatar sendo digital não consegue realizar. Desta forma, com menos significado o professor assiste à aula, participa nela e dá continuidade à atividade do avatar. Este cenário revela que o professor é indispensável na sala de aula e que não é substituído pela tecnologia, e, para além disso, revela que o docente necessita de ser competente no uso que faz dos recursos digitais, integrando-os numa metodologia com intencionalidade pedagógica, uma vez que "nenhum 
professor incompetente se transforma em bom pela utilização sistemática das tecnologias de informação e comunicação" (Estanqueiro, 2010, p. 37).

Importa ressalvar que, embora a criança tenha "um papel ativo no processo criativo" (Alencar \& Fleith, 2003, p. 7) é inegável o contributo e influência que o ambiente (fatores sociais, culturais e históricos) exerce sobre a mesma, sendo o papel do docente essencial na promoção da criatividade, incrementando não apenas intervenções favoráveis ao desenvolvimento desta competência, como também preparando o futuro cidadão para pensar e agir de forma criativa através da exploração, criação e argumentação.

\subsection{Impacto do avatar}

$\mathrm{Na}$ Educação Pré-Escolar (Figura 8) o avatar responde aos interesses das crianças e melhora a sua "motivação, o fascínio e a entrega no desenvolvimento da atividade", deixando visível "a sua satisfação pela expressão facial, vocal e emocional", como referem os estudantes estagiários. Além disso, embora menos significativo, melhora o ambiente educativo e o empenho das crianças.

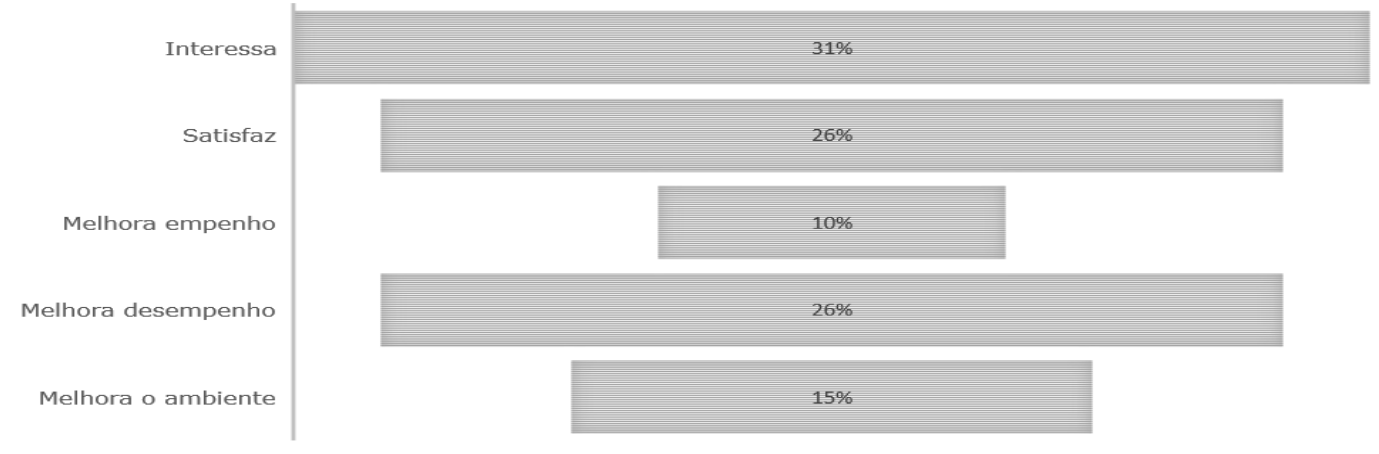

Figura 8. Impacto do avatar na Educação Pré-Escolar

No 10 CEB (Figura 9) esta aplicação tem um forte impacto na motivação das crianças e na sua predisposição para a tarefa. Também é relevante o impacto no entusiasmo, na promoção da comunicação, da participação, da autocrítica e autoavaliação. Um olhar global sobre todos os itens referidos pelos estudantes estagiários, verifica-se que o impacto envolve três dimensões importantes no processo educativo:

Atitude e sentimento da criança: ritmo de trabalho, predisposição para a tarefa, entusiasmo, empenho, motivação

- Competências: decisão, responsabilidade, autocrítica, autonomia, criatividade, autoavaliação, autocorreção

- Desenho metodológico: colaboração, proximidade, interação, comunicação, partilha, sequencialidade, articulação de saberes, valorização do trabalho, novidade, emoção. 


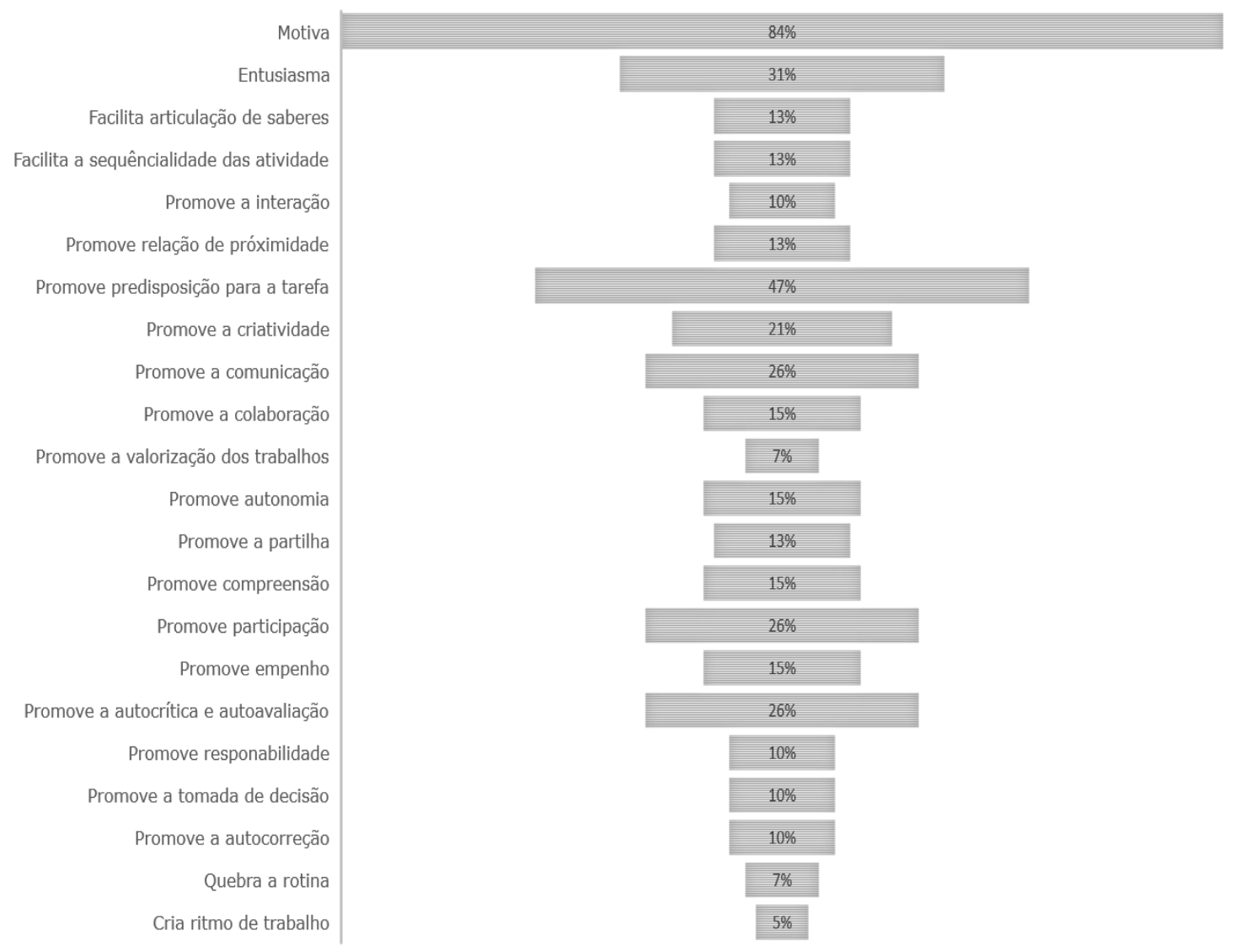

Figura 9. Impacto do avatar no $1 .{ }^{\circ} \mathrm{CEB}$

A análise dos resultados mostra que o uso de uma ferramenta digital como o Voki torna o processo de aprendizagem das crianças mais significativo e motivador porque, tal como afirmam Flores e Ramos (2016, p. 201) nas conclusões acerca de um estudo com o enfoque na mesma ferramenta no contexto de formação inicial de docentes do $1 .{ }^{\circ} \mathrm{CEB}$

"a) envolve o aluno na interação com o contexto real, com a articulação de saberes curriculares, com diferentes recursos digitais ou físicos, com eles mesmos e os outros; b) estimula a inclusão envolvendo todos os crianças nas tarefas e outros atores de educação, desafia novos ambientes de interesse dos alunos; c) orienta o agir do aluno de modo a que realize a aprendizagem facilmente e com satisfação, impõe liderança e controlo da situação; e d) promove a criatividade libertando o eu do aluno na construção do conhecimento e no respeito por si e pelo outro".

\section{Considerações finais}

O avatar assume diferentes funções ao longo da atividade/aula de acordo com o ato pedagógico, podendo assumir um papel mais tradicional ou mais construtivista, mas em todos os momentos motiva e desafia as crianças. Num momento mais tradicionalista, as crianças assumem um papel de recetor (escutam, interagem, realizam tarefas dirigidas), num momento mais construtivista desenvolvem outras capacidades: de criatividade, decisão e sentido estético (criação do avatar), de 
questionamento e raciocínio (construção e organização do conhecimento), de comunicação e argumentação (apresentação do avatar aos outros). Esta visão das TIC como instrumento é ainda um mito na decisão dos futuros educadores e professores, revelando necessidade de libertação de conceções e preconceitos para a transformação que o mundo necessita de trabalhar para o cidadão do século XXI. A aplicação fornecida - Voki, é simples, básica, acessível a qualquer criança e potenciadora da mudança, porém implica criatividade no modo de a utilizar. A mudança exige, assim, uma cultura que permita a recriação de projetos com novos recursos e novos modos de pensar e solucionar os problemas da atualidade.

Sabendo que os professores se desenvolvem por etapas (QuadrosFlores \& Raposo-Rivas, 2017) seria espectável que os estudantes que iniciaram a integração das TIC na Educação Básica, que mobilizaram conhecimento e reflexões nas didáticas específicas e metodologias da educação de infância no Mestrado, tivessem uma visão da integração das TIC não tanto como um instrumento, mas mais como alavanca para renovação das pedagogias e da educação. A perspetiva das políticas educativas atuais dá à centralidade da criança e do seu processo de aprendizagem uma importância relevante num ambiente securizante, contextualizador, diversificado e inclusive, multidisciplinar e integrador de vários agentes educativos (Lopes da Silva et al, 2016), pelo que estimulam a mudança e a curiosidade dos docentes no próprio cerne do sistema, podendo levar a bom termo projetos de inovação mais disruptivos.

No âmbito da formação inicial docente a disrupção é uma barreira na medida em que se depende da escola, do orientador cooperante e encarregados de educação. Contudo, a formação de futuros educadores e professores deve ter o cuidado de os fomentar para modelos pedagógicos ativos, que integram também recursos tecnológicos digitais, respondendo não só ao programa curricular, mas também à literacia digital e ao desenvolvimento de outras competências por forma a preparar futuros cidadãos do século XXI. Neste contexto, a criatividade é fundamental para que possam ser promotores de práticas alinhadas com a realidade atual, sendo que esta pode ser promovida em torno de três direções de trabalho: enfoque na criança, enfoque nos docentes, enfoque na escola como organização (Martinez, 2002). Será o trabalho colaborativo entre os diversos intervenientes a promover um olhar mais específico, mais sentido e envolvido, inscrito num registo mais criativo e participativo.

\section{Referências bibliográficas}

Alencar, E. \& Fleith, D. (2003). Contribuições teóricas recentes ao estudo da criatividade. Psicologia: Teoria e Pesquisa, 19(1), 1-8.

Bardin, L. (1977). Análise de Conteúdo. Lisboa: Edições 70.

Bogdan, R \& Boklen, S. (1994). Investigação qualitativa em educação: uma introdução à teoria e aos métodos. Porto: Porto Editora. 
Dotta, L., Marta, M., Ferreira, E. \& Diogo, F. (2013). O desenvolvimento da autonomia nos processos de formação de estudantes da Enfermagem e do Ensino. In A. Lopes (Org.), Formação Inicial de Professores e de Enfermeiros: identidades e ambientes (pp. 153-168). Porto, Edição: Mais Leituras.

Estanqueiro, A. (2010). Boas práticas na educação. O papel dos professores. Lisboa: Editorial Presença.

Flores, M. A. (2010). Algumas reflexões em torno da formação inicial de professores. Educação, 33(3), 182-188.

Flores, P., Escola, J., \& Peres, A. (2012). Formar para Inovar, Inovar Formando. In J. Rodriguez, C. Fernandez, \& D. Gonçalves. (Org.), TIC, Escola e Desenvolvimento. Projetos de inovação mediados pelas TIC (pp. 91 -98). Póvoa de Varzim: Escola Superior de Educação de Paula Frassinetti e Nova Escola Galega.

Flores, P., Escola, J., \& Peres, A. (2013). Identidade Profissional Docente e as TIC: estudo de boas práticas no $1^{0} \mathrm{CEB}$ na região do Porto. In J. Raposo-Rivas, M., Figueira, \& F., Aires (Coords.). As TIC no Ensino: Politicas, Usos e Realidades (pp.323-342). Santiago de Compostela: Andavira Editora.

Flores, P., \& Ramos, A. (2016). Práticas com TIC potenciadoras de mudança. 1.o Encontro Internacional de Formação na Docência (INCTE) (pp. 195-203). Bragança: Instituto Politécnico de Bragança.

Korthagen, F., Loughram, J. \& Russell, T. (2013). Desenvolvimento dos princípios fundamentais para os programas e as práticas de formação de professores. In A. Lopes (Orgs.), Formação Inicial de Professores e de Enfermeiros: Identidades e Ambientes (pp.19-54). Porto. Edição: Mais Leituras.

Latorre, A. (2003). La investigación-acción. Conocer y cambiar la prática educativa. Barcelona. Editorial Graó

Lopes da Silva, I., Marques, L., Mata, L., \& Rosa, M. (2016). Orientações Curriculares para a Educação Pré-Escolar. Ministério da Educação/DireçãoGeral de Educação (DGE).

Marta, M. (2017). As TIC no Jardim de Infância: uma motivação pedagógica ou uma distração. Revista de estúdios e investigación en psicologia y educación, 43-46. https://goo.gl/hViN2n

Martinez, A. (2002). A criatividade na escola: três direções de trabalho. Linhas Críticas, 8(15), 189-206.

Martins, I. (2015). Formação inicial de professores. Um debate inacabado. In M. Miguéns (Coord.), Formação inicial de professores (pp. 176-190). Lisboa: Conselho Nacional de Educação.

Nóvoa, A. (1991). O Passado e o Presente dos Professores. In A. Nóvoa (Org.), Profissão Professor (pp. 15-39). Porto: Porto Editora.

Nóvoa, A. (2002). Formação de Professores e Trabalho Pedagógico. Lisboa: Educa.

Oliveira, E. \& Alencar, E. (2012). Importância da criatividade na escola e no trabalho docente segundo coordenadores pedagógicos. Estudos de Psicologia, 29(4), 541-552. 
revista 48 practicum

Oliveira-Martins, G. (Coord.) (2017). O perfil dos alunos à saída da escolaridade obrigatória. Lisboa: Ministério da Educação.

Ponte, J. P. (1994). O Projecto Minerva: Introduzindo as NTI Na Educação Em Portugal: Minerva - Relatório do Projecto MINERVA. Ministério da Educação.

Quadros-Flores, P. \& Raposo-Rivas, M. (2007). A inclusão de tecnologias digitais na educação: (re)construção da identidade profissional docente na prática. Revista Prácticum, 2(2) 2-17. https://goo.gl/aDGe2D

Ribeiro, A. (2018). O Mistério da Criatividade. Teorias e práticas criativas nas Ciências e nas Artes, na vida quotidiana e na Educação. Porto: Edições Afrontamento.

Ruivo, J. (2015). Formar professores, melhorar a escola, mudar a sociedade. In M. Miguéns (Coord.), Formação inicial de professores (pp. 166-174). Lisboa: Conselho Nacional de Educação.

Silva, M. C. \& Sarmento, T. (2017). O brincar na infância é um assunto sério. In T. Sarmento, I. Ferreira \& R. Madeira (Orgs.), Brincar e Aprender na Infância (pp. 39-56). Porto: Porto Editora.

Shulman, L. (2014). Conhecimento e ensino: fundamentos para a nova reforma. Cadernoscenpec, 4(2), 196-229.

Vieira, F. \& Moreira, M. A. (2011). Supervisão e avaliação do desempenho docente. Para uma abordagem de orientação transformadora. Lisboa: Ministério da Educação-Conselho Científico para a avaliação de professores.

\section{Normativos legais}

Despacho n. ${ }^{\circ}$ 5908/2017, 5 de julho, publicado no Diário da República n. ${ }^{\circ}$ 128/2017, Série II de 2017-07-05 - Autoriza, em regime de experiência pedagógica, a implementação do projeto de autonomia e flexibilidade curricular dos ensinos básico e secundário, no ano escolar de 2017-2018. Ministério da Educação - Gabinete do Secretário de Estado da Educação.

Despacho n.o 6478/2017, 26 de julho, publicado no Diário da República n. 0 143/2017, Série II de 2017-07-26 - Homologa o Perfil dos Crianças à Saída da Escolaridade Obrigatória. Ministério da Educação - Gabinete do Secretário de Estado da Educação. 